\title{
Cluster Formation in Plasticized Poly(phenylene oxide) Ionomers
}

\author{
Hee-Seok Kim, Joon-Seop Kim, ${ }^{\dagger}$ Jin-Wook SHIN, ${ }^{*}$ \\ and Young-Kwan LEE** \\ Department of Polymer Science \& Engineering, Chosun University, Kwangju 501-759, Korea \\ * Department of Chemistry, McGill University, Montreal PQ H3A 2K6, Canada \\ ** Department of Chemical Engineering, Sung Kyun Kwan University, Suwon 440-746, Korea
}

(Received April 27, 1998)

KEY WORDS Poly(phenylene oxide) / Ionomer / Plasticization / Glass Transition / Cluster /

Ionomers are polymers containing relatively small amounts of ionic groups, attached to nonionic polymer backbone chains. ${ }^{1,2}$ Ionic groups form ion aggregates, or multiplets, ${ }^{3}$ which influence the properties of polymers significantly. In many ionomer systems, a small-angle X-ray scattering (SAXS) peak $^{4-8}$ and two glass transitions $\left(T_{\mathrm{g}} \mathrm{s}\right)^{9}$ have been observed. In 1990, the multipletcluster model, the Eisenberg-Hird-Moore (EHM) mod$\mathrm{el},{ }^{10}$ was proposed to interpret SAXS and mechanical data of random ionomers. According to the model, the multiplet acts as a physical crosslink which induces reduction in chain mobility surrounding the multiplet. The size of the restricted mobility region is not large enough to show its own $T_{\mathrm{g}}$. However, as ion concentration increases, the restricted mobility regions start to overlap. Eventually, regions become large enough to have their own $T_{\mathrm{g}}$. These regions are called clusters, and the ionomers behave as two-phase material.

Hseih and Peiffer ${ }^{11}$ investigated the miscibility of blends of poly(2,6-dimethyl-1,4-phenylene oxide) (PPhO)polystyrene (PS), sulfonated $\mathrm{PPhO}(\mathrm{NaSPPhO})$ ionomerPS, PPhO-sulfonated PS (SPS) ionomer, and NaSPPhO ionomer-SPS ionomer. They found that the miscibility of blends depends on the sulfonation of ionomers. The unfunctionalized polymer blends are miscible over the whole composition range, but miscibility is reduced upon functionalization. The miscibility of blends of similar polymer pairs was investigated by Register and Bell, ${ }^{12}$ Bazuin et al., ${ }^{13}$ Tomita and Register, ${ }^{14}$ and Pan et al. ${ }^{15}$ Vulkovic et al. ${ }^{16}$ studied the phase-behavior of sulfonated PPhO ionomer blends with poly(styrene-co-bromostyrene).

Lee and Lee ${ }^{17}$ investigated the properties of sulfonated PPhO ionomers. The glass transition temperature of the ionomer was found to increase with sulfonation, and that there is a $\beta$-transition at $40^{\circ} \mathrm{C}$ below the matrix $T_{\mathrm{g}}$. They reported that the NaSPPhO ionomer shows a thermal decomposition at ca. 230 to $260^{\circ} \mathrm{C}$. In this temperature range, the bonds between a benzene ring of a polymer chain and a sulfonate group may break. They observed a weak SAXS peak of the ionomer, and proposed that the ionomer forms only weak ion aggregates because of the rigidity of $\mathrm{PPhO}$ polymer chains.

In some ionomer systems, clustering is induced by plasticization. Examples include plasticized systems of

\footnotetext{
† To whom all correspondence should be addressed.
}

poly(styrene-co-4-vinylpyridinium methyl iodide) ${ }^{18}$ and poly(methyl methacrylate-co-cesium methacrylate) ${ }^{19}$ ionomers. Thus, in the present study, we investigated the effects of plasticization on cluster formation in the $\mathrm{NaSPPhO}$ ionomer system and determined whether we can observe a cluster $T_{\mathrm{g}}$ by lowering the glass transition temperature of the $\mathrm{NaSPPhO}$ ionomer via plasticization. This study was carried out to answer to the question as to why the unplasticized ionomer having multiplets does not show a cluster glass transition.

\section{EXPERIMENTAL}

\section{Sulfonation}

A poly(2,6-dimethyl-1,4-phenylene oxide) ( $\mathrm{PPhO})$ sample of $M_{w}=c a .200000$ was obtained from Aldrich. The method of Makowski et al. ${ }^{20}$ for homogeneous sulfonation was used to produce the sulfonated PPhO ( NaSPPhO) sample. To determine ion concentration, the sample was dissolved in a benzene-methanol $(9: 1, \mathrm{v} / \mathrm{v})$ mixture to make a $5 \%(\mathrm{w} / \mathrm{v})$ solution, and titrated with standard methanolic sodium hydroxide to the phenolphthalein end point. Ion content was ca. $5.7 \mathrm{~mol} \%$. Neutralization of the acid groups was achieved by adding a predetermined quantity of methanolic sodium hydroxide to $5 \%(\mathrm{w} / \mathrm{v})$ ionomer solution in a benzenemethanol $(9: 1, \mathrm{v} / \mathrm{v})$ mixture. The solution was freeze dried and then dried further under vacuum at $175^{\circ} \mathrm{C}$ for 1 day.

\section{Plasticization}

Plasticized ionomers were obtained by dissolving the ionomers in a mixed solvent of benzene-methanol $(9: 1$, $\mathrm{v} / \mathrm{v}$ ) and adding dioctyl phthalate (DOP) to the ionomer solution. The ionomer-plasticizer blends were freezedried and further dried under vacuum at $80^{\circ} \mathrm{C}$ for 2 days.

\section{Sample Preparation}

For DMTA measurement, the samples were compression molded at $30 \mathrm{MPa}$. Sample notations and molding temperatures are listed in Table I. The samples molded at high temperatures were quenched to remove crystallinity which might influence mechanical properties. Sample notation for the plasticized sodium sulfonated $\mathrm{PPhO}$ ionomer is NaSPPhO- $x$, where $x$ indicates $\mathrm{wt} \%$ of DOP in a sample. The dimensions of the molded 
Table I. Sample notations and molding temperature

\begin{tabular}{lc}
\hline Sample notation & Molding temperature $/{ }^{\circ} \mathrm{C}$ \\
\hline PPhO & 290 \\
NaSPPhO & 270 \\
PPhO-33 & 150 \\
NaSPPhO-4 & 250 \\
NaSPPhO-9 & 220 \\
NaSPPhO-17 & 200 \\
NaSPPhO-24 & 180 \\
NaSPPhO-31 & 170 \\
\hline
\end{tabular}

samples were approximately $2.5 \times 6.5 \times 30 \mathrm{~mm}$.

\section{Dynamic Mechanical Thermal Analysis (DMTA)}

Mechanical measurement was performed using a Polymer Laboratories Mark II dynamic mechanical thermal analyzer (DMTA) in the dual cantilever bending mode, at frequencies of $0.3,1,3,10$, and $30 \mathrm{~Hz}$ and heating rate of $1{ }^{\circ} \mathrm{Cmin}^{-1}$. For each sample, the storage modulus $\left(E^{\prime}\right)$ and loss modulus $\left(E^{\prime \prime}\right)$ were obtained as functions of temperature.

\section{RESULTS AND DISCUSSION}

Figure 1 shows the storage and loss moduli of $\mathrm{PPhO}$ and $\mathrm{NaSPPhO}$ samples as functions of temperature at $1 \mathrm{~Hz}$. For the $\mathrm{PPhO}$ sample, the polymer shows a glassy modulus up to $210^{\circ} \mathrm{C}$, and above that temperature the modulus starts to drop rapidly. For the $\mathrm{NaSPPhO}$ sample, drop in the modulus starts at $c a .220^{\circ} \mathrm{C}$. The rubbery moduli at $270^{\circ} \mathrm{C}$ are $6.3 \times 10^{6} \mathrm{~Pa}$ for the $\mathrm{NaSPPhO}$ and $0.8 \times 10^{6} \mathrm{~Pa}$ for the PPhO. This is due to the presence of multiplets which act as physical crosslinks. Similar results were observed for poly(styreneco-sodium methacrylate) ionomers. ${ }^{21}$

We determined the peak in the $\log E^{\prime \prime}$ curve as a glass transition temperature $\left(T_{\mathrm{g}}\right)$; the $T_{\mathrm{g}}$ of the $\mathrm{NaSPPhO}$ is ca. $228^{\circ} \mathrm{C}$, which is $c a .6^{\circ} \mathrm{C}$ higher than that of the $\mathrm{PPhO}$ polymer. The higher $T_{\mathrm{g}}$ of the ionomer is owing to the presence of multiplets and copolymerization effect. ${ }^{22}$ The increase in $T_{\mathrm{g}}$ by ionization is larger for the SPS case than for the NaSPPhO ionomers at a comparable ion content. This is due to the fact that the PPhO polymer chain has a higher $T_{\mathrm{g}}\left(\mathrm{ca} \cdot 210^{\circ} \mathrm{C}\right.$ by DSC) than PS polymer $\left(c a .100^{\circ} \mathrm{C}\right.$ by DSC), ${ }^{23}$ and thus the $\mathrm{PPhO}$ polymer chain has some difficulty in forming multiplets. The NaSPPhO ionomer should thus have smaller and fewer multiplets than the SPS ionomer does. ${ }^{2}$

The mechanical properties of DOP-plasticized $\mathrm{PPhO}$ and NaSPPhO samples are shown in Figure 2. The storage modulus for the plasticized NaSPPhO samples starts to decrease at lower temperatures as the plasticizer content increases. When one looks at the $\log E^{\prime \prime}$ curves, one sees one peak at $c a .80^{\circ} \mathrm{C}$ and a shoulder at $c a .100^{\circ} \mathrm{C}$ for the plasticized homopolymer, while two peaks are observed for the plasticized NaSPPhO ionomers. The shoulder is thought to be associated probably with crystallization behavior in the $\mathrm{PPhO}$ polymer. The temperatures of the peak at lower temperatures are 126,119 , and $109^{\circ} \mathrm{C}$, and those at higher temperatures are 220,216 , and $211^{\circ} \mathrm{C}$ for the ionomers containing 17,24 , and $31 \mathrm{wt} \%$ of DOP, respectively. The high-

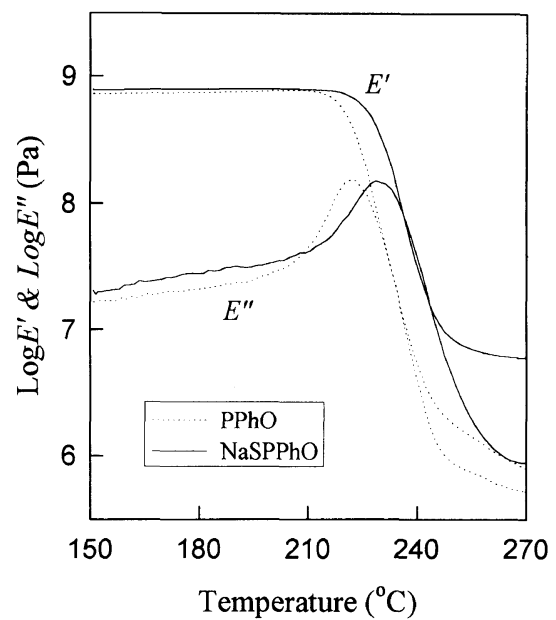

Figure 1. Storage modulus $\left(E^{\prime}\right)$ and loss modulus $\left(E^{\prime \prime}\right)$ as functions of temperature for $\mathrm{PPhO}$ and NaSPPhO samples, measured at $1 \mathrm{~Hz}$.

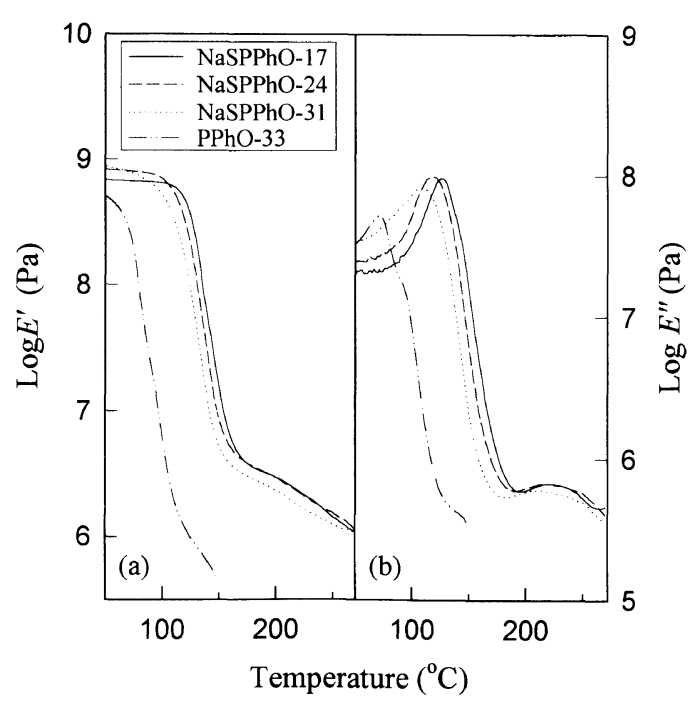

Figure 2. (a) Storage modulus $\left(E^{\prime}\right)$ and (b) loss modulus $\left(E^{\prime \prime}\right)$ as functions of temperature for plasticized PPhO and NaSPPhO samples, measured at $1 \mathrm{~Hz}$.

temperature peak is probably due to the cluster $T_{\mathrm{g}}$, and similar results were observed for the plasticized SPS ionomer system. ${ }^{24}$ The nonpolar plasticizer, DOP, molecules reside in nonpolar matrix and cluster regions, but not in polar multiplets. With increasing plasticizer content, the matrix $T_{\mathrm{g}}$ decreases, and cluster $T_{\mathrm{g}}$ drops. If the plasticizer is added sufficiently, the cluster $T_{\mathrm{g}}$ is observed below the thermal decomposition temperature (ca. $270^{\circ} \mathrm{C}$ : This temperature in DMTA experiments is relevant to $c a .250^{\circ} \mathrm{C}$ in DSC and TGA studies). As the matrix $T_{\mathrm{g}}$ drops, the kinetic energy of the polymer chains, $\mathrm{k} T_{\mathrm{g}}$, decreases. Thus, the flexibility of polymer chains increases to facilitate multiplet formation. These two factors contribute to cluster $T_{\mathrm{g}}$ peak formation at $c a$. $220^{\circ} \mathrm{C}$.

Matrix and cluster $T_{\mathrm{g}} \mathrm{s}$ are shown as functions of the amount of plasticizer in Figure 3. In the figure, the matrix $T_{\mathrm{g}}$ decreases rapidly with increasing DOP content from 0 to $10 \mathrm{wt} \%$ [ca. $-8.5^{\circ} \mathrm{C} /(\mathrm{wt} \%$ of DOP $\left.)\right]$. Above that plasticizer content, $T_{\mathrm{g}}$ decreases gently $\left[\mathrm{ca} .-1^{\circ} \mathrm{C} /(\mathrm{wt} \%\right.$ of DOP)]. For samples containing below $10 \mathrm{wt} \%$ of plasticizers, reliable cluster $T_{\mathrm{g}}$ data were not obtained 


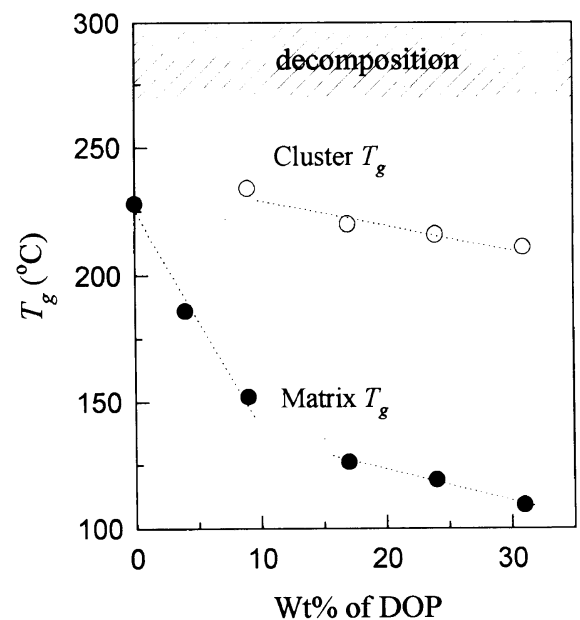

Figure 3. Matrix and cluster glass transition temperatures measured from peaks of $\log E^{\prime \prime}$ curve (at $1 \mathrm{~Hz}$ ) for unplasticized and plasticized ionomers as functions of $w \mathrm{t} \%$ of DOP.

Table II. Activation energies $\left(E_{\mathrm{a}}\right)$ of matrix and cluster $T_{\mathrm{g}} \mathrm{s}$

\begin{tabular}{|c|c|c|}
\hline \multirow{2}{*}{$\begin{array}{l}\text { Sample } \\
\text { notation }\end{array}$} & $E_{\mathrm{a}}$ for the matrix $T_{\mathrm{g}}$ & $E_{\mathrm{a}}$ for the cluster $T_{\mathrm{g}}$ \\
\hline & $\mathrm{kJ} \mathrm{mol}^{-1}$ & $\mathrm{~kJ} \mathrm{~mol}^{-1}$ \\
\hline $\mathrm{PPhO}$ & 1280 & - \\
\hline $\mathrm{NaSPPhO}$ & 980 & - \\
\hline PPhO-33 & 980 & - \\
\hline NaSPPhO-17 & 650 & 250 \\
\hline NaSPPhO-24 & 500 & 240 \\
\hline NaSPPhO-31 & 460 & 230 \\
\hline
\end{tabular}

because $T_{\mathrm{g}}$ was very close to and even above the thermal decomposition temperature. When plasticizer content is ca. 10 to $30 \mathrm{wt} \%$, the cluster $T_{\mathrm{g}}$ decreases with increasing DOP content at $c a .-1{ }^{\circ} \mathrm{C} /(\mathrm{wt} \%$ of DOP). Cluster $T_{\mathrm{g}}$ as a function of wt $\%$ of DOP is similar to that of matrix $T_{\mathrm{g}}$. One can obtain the cluster $T_{\mathrm{g}}$ of an unplasticized ionomer by extrapolation to $0 \mathrm{wt} \%$ of plasticizer. The extrapolated cluster $T_{\mathrm{g}}$ is $>300^{\circ} \mathrm{C}$, which is far above the bond-breakage temperature of the ionic groups from the benzene rings. Thus, we cannot obtain cluster $T_{\mathrm{g}}$ of the unplasticized ionomer.

Activation energies $\left(E_{\mathrm{a}} \mathrm{s}\right)$ for matrix and cluster glass transitions were calculated using Arrhenius plots of log frequency $v s$. inverse temperature. Activation energies are listed in Table II.

$E_{\mathrm{a}}$ for matrix $T_{\mathrm{g}}$ of $\mathrm{PPhO}$ is $c a .1280 \mathrm{~kJ} \mathrm{~mol}^{-1}$, while that of the PPhO polymer containing $33 \mathrm{wt} \%$ DOP (PPhO-33) is ca. $980 \mathrm{~kJ} \mathrm{~mol}^{-1}$. For the unplasticized ionomer, $E_{\mathrm{a}}$ for the matrix glass transition is $c a .980$ $\mathrm{kJ} \mathrm{mol}^{-1}$. For the plasticized ionomers, $E_{\mathrm{a}} \mathrm{s}$ for the matrix $T_{\mathrm{g}}$ are $c a .460-650 \mathrm{~kJ} \mathrm{~mol}^{-1}$, while those for the cluster $T_{\mathrm{g}}, 240 \mathrm{~kJ} \mathrm{~mol}^{-1}$. These activation energies are similar to those of the plasticized Na neutralized SPS ionomers, in which $E_{\mathrm{a}} \mathrm{s}$ for the matrix and cluster $T_{\mathrm{g}} \mathrm{s}$ were $c a .500 \mathrm{~kJ} \mathrm{~mol}^{-1}$ and $c a .200 \mathrm{~kJ} \mathrm{~mol}^{-1}$, respectively. ${ }^{25}$ This implies that activation at $T_{\mathrm{g}} \mathrm{s}$ may be similar in the two plasticized ionomer systems. The very similar $E_{\mathrm{a}} \mathrm{s}$ for the cluster $T_{\mathrm{g}}$ suggest that ion-hopping of sodium sulfonate groups, possessed by these two systems, is involved strongly in cluster glass transition mechanisms of the two ionomer systems. ${ }^{2,26,27}$

Acknowledgment. This study was supported by a research fund from Chosun University, 1997.

\section{REFERENCES AND NOTES}

1. A. Eisenberg and M. King, "Ion-Containing Polymers, Physical Properties and Structure," Academic Press, New York, N.Y., 1977.

2. A. Eisenberg and J.-S. Kim, "Introduction to Ionomers," Wiley, New York, N.Y., 1998.

3. A. Eisenberg, Macromolecules, 3, 147 (1970).

4. F. C. Wilson, R. Longworth, and D. J. Vaughan, Polym. Prepr. (Am. Chem. Soc., Div. Polym. Chem.), 9, 505 (1968).

5. C. L. Marx, D. F. Caulfield, and S. L. Cooper, Macromolecules, 6, 344 (1973).

6. W. J. MacKnight, W. P. Taggart, and R. S. Stein, J. Polym. Sci., Polym. Symp., 45, 113 (1974).

7. M. Fujimura, T. Hashimoto, and H. Kawai, Macromolecules, 14, 1309 (1982).

8. R. B. Moore, D. Bittencourt, M. Gauthier, C. E. Williams, and A. Eisenberg, Macromolecules, 24, 1376 (1991).

9. B. Hird and A. Eisenberg, J. Polym. Sci., Polym. Phys., Ed., 28, 1665 (1990)

10. A. Eisenberg, B. Hird, and R. B. Moore, Macromolecules, 23, 4098 (1990).

11. D. T. Hseih and D. G. Peiffer, Polymer, 33, 1210 (1992).

12. R. A. Register and T. R. Bell, J. Polym. Sci., Part B, Polym. Phys., 30, 569 (1992).

13. C. G. Bazuin, L. Rancourt, S. Villeneuve, and A. Soldera, J. Polym. Sci., Part B, Polym. Phys., 31, 1431 (1993).

14. H. Tomita and R. A. Register, Macromolecules, 26, 2796 (1993).

15. Y. Pan, Y. Huang, B. Liao, M. Chen, G. Cong, and L. M. Leung, J. Appl. Polym. Sci., 65, 341 (1997).

16. R. Vukovic, G. Bogdanic, A. Erceg, D. Fles, F. E. Karasz, and W. J. MacKnight, Polymer, 39, 2847 (1998).

17. Y.-K. Lee and C. H. Lee, Polymer (Korea), 20, 191 (1996).

18. D. Wollmann, C. E. Williams, and A. Eisenberg, Macromolecules, 25, 6775 (1992).

19. J.-S. Kim, H.-S. Kim, and A. Eisenberg, Bull. Korean Chem. Soc., 19, 623 (1998).

20. H. S. Makowski, R. D. Lundberg, and G. L. Singhal, U. S. Patent 870841 (1975).

21. J.-S. Kim, R. J. Jackman, and A. Eisenberg, Macromolecules, 27, 2789 (1994).

22. The glass transition temperatures for random copolymers change with composition between those of the homopolymers, which is a copolymerization effect.

23. J. Brandrup and E. H. Immergut, Ed., "Polymer Handbook," John Wiley \& Sons, New York, N.Y., 1988.

24. R. A. Weiss and J. J. Fitzgerald, J. Polym. Sci., Part B, Polym. Phys., 24, 1064 (1991).

25. J.-S. Kim, S. B. Roberts, A. Eisenberg, and R. B. Moore, Macromolecules, 26, 5256 (1993).

26. B. Hird and A. Eisenberg, Macromolecules, 25, 6466 (1992).

27. J.-S. Kim, K. Yoshikawa, and A. Eisenberg, Macromolecules, 27, 6347 (1994). 